\title{
Feasibility Analysis of Enterprise Reserve and Preparation Material under the Condition of Civil and Military Integration
}

\author{
JIA Hai-rong1, a, GAO Gui-qing 2, b, WANG Kang 3, c \\ 1,2,3Xi'an High-tech Research Institute 710025, China. \\ ajia.qq594567239com@qq.com
}

Key words: readiness supplies, Delphi method, feasibility analysis.

\begin{abstract}
In the current stage, military and civilian integration has risen to a national strategy. The military and civilian integration of military reserve stocks for supplies can be chosen by local enterprises, and the demonstration should be conducted on this proposal. Finally write a report to determine whether this project is feasible or not, for policy makers to choose. This article uses the Delphi method to make a comprehensive evaluation of the plans of local enterprises for storage and readiness of materials, in order to improve the accuracy of the report and to study the feasibility of the project using quantitative methods.
\end{abstract}

\section{Introduction}

The most important model for the integration of military and civilian reserve for reserve readjustment is to have the local logistics enterprises prepare for storage. The general procedure for reporting the feasibility of this project is to rely on a large amount of research data to support and experts evaluate the indicators and draw conclusions. Use the qualitative method to draw the project's feasibility or not. This article comprehensively discusses the results of the feasibility study report of the local enterprises on behalf of storage and readiness materials project. Delphi method, a total of 12 experts to evaluate the project to draw the project feasibility.

\section{Concept}

Feasibility. The degree of feasibility of this paper expressed as 0-10, as shown in Figure 1. Expert evaluation of the evaluation value of 0 to 10,0 value that is extremely infeasible, 10 that is entirely feasible.

\section{Extremely impractical 1224456789910 Completely feasible}

Fig. 1

The corresponding evaluation value is $\mathrm{x}$, expressed in qualitative language: $0<\mathrm{x} \leq 1$ (including 1) is extremely infeasible, $1<x \leq 3$ (including 3) is not feasible, $3<x \leq 4$ It is practicable that $4<x \leq 6$ (including 6), $6<x \leq 8$ (including 8) is feasible, $8<x \leq 9$ (including 9) is feasible, and $9<\mathrm{x} \leq 10$ is completely feasible. Evaluation value of 8 or more, said the project investment risk is small, greater than 9 , that basically no risk.

Many experts evaluate the value of the matrix. A number of experts to evaluate the indicators of the project scoring, evaluation results in Table 1. 
Table 1 Score Table

\begin{tabular}{|c|c|c|c|c|c|}
\hline Endex & Expert1 & Expert2 & Expert3 & $\ldots$ & Expert \\
\hline Index 1 & $\mathbf{E}_{11}$ & $\mathbf{E}_{12}$ & $\mathbf{E}_{13}$ & $\ldots$ & $\mathbf{E}_{1 n}$ \\
\hline Index 2 & $\mathbf{E}_{21}$ & $\mathbf{E}_{22}$ & $\mathbf{E}_{23}$ & $\ldots$ & $\mathbf{E}_{2 n}$ \\
\hline Index 3 & $\mathbf{E}_{31}$ & $\mathbf{E}_{32}$ & $\mathbf{E}_{33}$ & $\ldots$ & $\mathbf{E}_{3 n}$ \\
\hline$\ldots$ & $\ldots$ & $\ldots$ & $\ldots$ & $\ldots$ & $\ldots$ \\
\hline Index m & $\mathbf{E}_{m 1}$ & $\mathbf{E}_{m 1}$ & $\mathbf{E}_{m 3}$ & $\ldots$ & $\mathbf{E}_{m n}$ \\
\hline
\end{tabular}

Consistency Judgment Conditions. As a result of using a number of expert scoring model, the difference between different experts, evaluation scoring will be different, we use the method of centralized indicators.

$$
\left|\mathbf{E}_{x y}-\frac{1}{n} \mathfrak{a}_{y=1}^{n} \mathbf{E}_{x y}\right| £ \delta
$$

Where $\mathrm{x}=1,2,3, \ldots, \mathrm{m} ; \mathrm{y}=1,2,3, \ldots \mathrm{n}$; Allowable deviations for expert scoring, $\delta$, individual scoring values can not exceed the average of all expert values. This article takes a value of 2 , the higher the value, the smaller the value.

To establish the index system. The first-level indicators of local logistics enterprises 'storage and readiness materials project are as follows: marketability (market development level of logistics enterprises), technology (technical level of logistics enterprises' reserve turnover), financial capability (military budget and enterprise reserve fees), tasks Security benefits (logistics delivery accuracy level), human resources (military personnel and enterprise human resources), risk control capability (ability of enterprises to deal with unexpected situations), and set the corresponding second-level indicators for each level of indicators.

In order to determine the weights of each index, the basic steps are as follows: First, the weight of each index is determined by using AHP's qualitative and quantitative system analysis method.

1.Establish the hierarchical structure, 6 first-level indicators and 20 corresponding second-level indicators according to the first-level indicators and the second-level indicators corresponding to local enterprises' evaluation;

2. According to the upper level as the judgment criterion, relevant experts set up the judgment matrix according to the nine scales according to the nine scales. The first level index establishes the judgment matrix based on the enterprise marketability index as the judgment criterion. The second level index takes the first level index as Judgment criteria to establish the judgment matrix.

3. Solving the most eigenvalue and eigenvector of the judgment matrix by sum-product method, we get the ranking weight of the relative importance of some element corresponding to the upper level.

4. To test the consistency of the judgment matrix.If you do not meet the consistency test, adjust the value of the judgment matrix element. Then step (3), (4) to calculate, until the consistency test is satisfied. Indicator system and weight as shown in Table 2. 
Table 2 index system

\begin{tabular}{|c|c|c|}
\hline $\begin{array}{l}\text { First level indicator } \\
\text { (weight) }\end{array}$ & Secondary indicators & Weights \\
\hline \multirow{4}{*}{ Market-oriented ability } & International competition & 0.05 \\
\hline & Domestic competition & 0.05 \\
\hline & Market development scale & 0.05 \\
\hline & Competitive Advantage & 0.05 \\
\hline \multirow{3}{*}{ technology $(0.2)$} & Reserve technology & 0.1 \\
\hline & Turnaround Technology & 0.05 \\
\hline & Transport technology & 0.05 \\
\hline \multirow{3}{*}{ Financial ability $(0.1)$} & Military budget & 0.05 \\
\hline & Business fees & 0.025 \\
\hline & Funding reserve & 0.025 \\
\hline \multirow{3}{*}{ Mission protection } & Material delivery accuracy & 0.05 \\
\hline & Task completion amount & 0.1 \\
\hline & $\begin{array}{l}\text { After delivery material } \\
\text { well }\end{array}$ & 0.05 \\
\hline \multirow{3}{*}{ Human Resources ( 0.2 ) } & $\begin{array}{c}\text { Military and business } \\
\text { docking }\end{array}$ & 0.1 \\
\hline & Technical personnel & 0.05 \\
\hline & Managerial talent & 0.05 \\
\hline \multirow{4}{*}{ Wind control ability } & Technical risk control & 0.025 \\
\hline & $\begin{array}{c}\text { Material deterioration } \\
\text { damage risk control }\end{array}$ & 0.025 \\
\hline & $\begin{array}{c}\text { Unpredictable risk control } \\
\text { in the market }\end{array}$ & 0.025 \\
\hline & $\begin{array}{c}\text { Corporate Operational } \\
\text { Risk Control }\end{array}$ & 0.025 \\
\hline
\end{tabular}


Figue2 the step

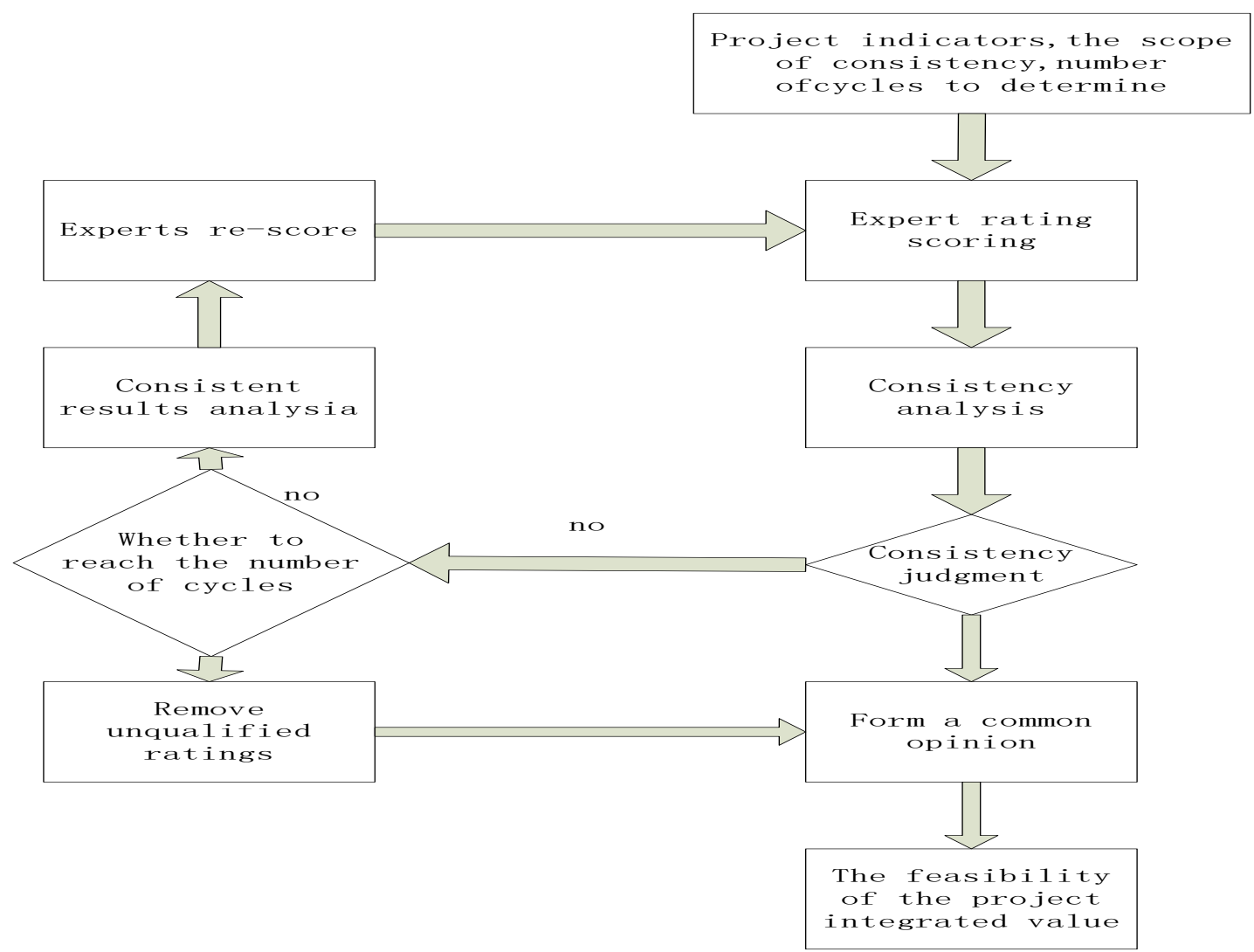

Delphi method work steps. Delphi method is widely used in the forecast, the use of more and more mature. This step is shown in Figure 2

Use Delphi method to analyze the feasibility of local stockpiling and readiness supplies of local enterprises. According to the work steps in Figure 2, the process is as follows:

The first step is to select 12 experienced experts in expert research, provide local enterprises with projects for storage and readiness of supplies and materials in advance, and report the market development of the enterprises in recent years, and introduce the assessment process and the grading requirements. The error of consistency is not more than 2 , The number of cycles does not exceed 3 times;

The second step, experts according to their own analysis of the situation, scoring table in Table 
Table 3 Scorecard

\begin{tabular}{|c|c|c|c|}
\hline First level indicator (weight) & Secondary indicators & Weights & Score \\
\hline \multirow{4}{*}{ Market-oriented ability } & International competition & 0.05 & \\
\hline & Domestic competition & 0.05 & \\
\hline & Market development scale & 0.05 & \\
\hline & Competitive Advantage & 0.05 & \\
\hline \multirow{3}{*}{ technology $(0.2)$} & Reserve technology & 0.1 & \\
\hline & Turnaround Technology & 0.05 & \\
\hline & Transport technology & 0.05 & \\
\hline \multirow{3}{*}{ Financial ability ( 0.1 ) } & Military budget & 0.05 & \\
\hline & Business fees & 0.025 & \\
\hline & Funding reserve & 0.025 & \\
\hline \multirow{3}{*}{$\begin{array}{l}\text { Mission protection benefits } \\
\qquad(0.2)\end{array}$} & Material delivery accuracy & 0.05 & \\
\hline & Task completion amount & 0.1 & \\
\hline & After delivery material well & 0.05 & \\
\hline \multirow{3}{*}{ Human Resources ( 0.2 ) } & $\begin{array}{l}\text { Military and business } \\
\text { docking }\end{array}$ & 0.1 & \\
\hline & Technical personnel & 0.05 & \\
\hline & Managerial talent & 0.05 & \\
\hline \multirow{4}{*}{ Wind control ability $(0.1)$} & Technical risk control & 0.025 & \\
\hline & $\begin{array}{c}\text { Material deterioration } \\
\text { damage risk control }\end{array}$ & 0.025 & \\
\hline & $\begin{array}{c}\text { Unpredictable risk control in } \\
\text { the market }\end{array}$ & 0.025 & \\
\hline & $\begin{array}{c}\text { Corporate Operational Risk } \\
\text { Control }\end{array}$ & 0.025 & \\
\hline
\end{tabular}

The third step is to collect experts scoring tables, experts do not meet, pass the mail, organize the data, written in matrix form; 


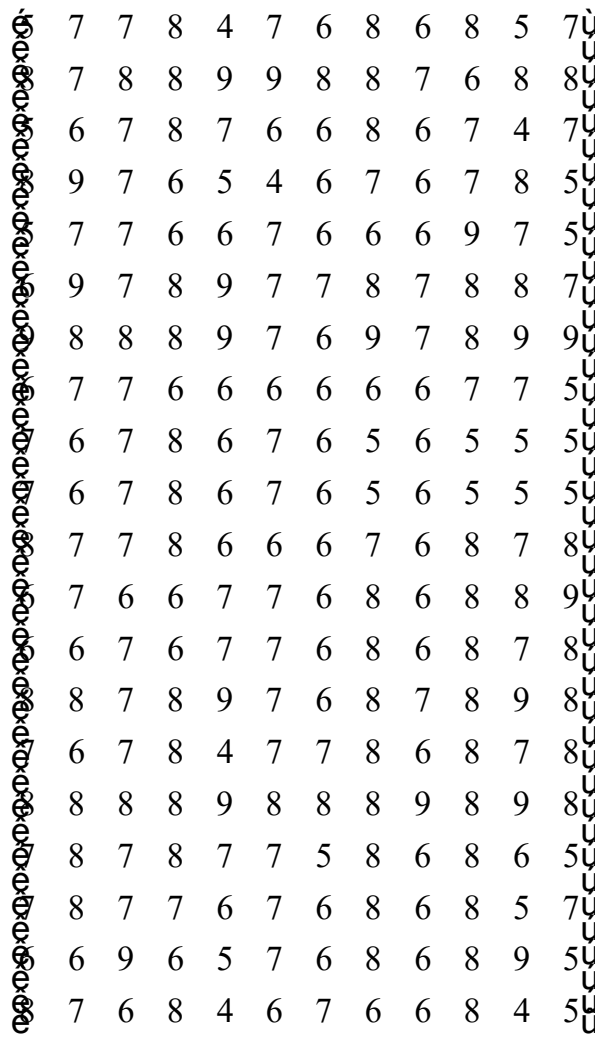

By calculating the deviation from the consistency of the value of the results shown in Table 4, marked out of the allowable range of values.

Table 4 Results of the first round of conformance analysis

\begin{tabular}{|c|c|c|c|c|c|c|c|c|c|c|c|c|}
\hline & 1 & 2 & 3 & 4 & 5 & 6 & 7 & 8 & 9 & 10 & 11 & 12 \\
\hline 1 & 1.417 & 0.417 & 0.583 & 1.583 & 0.583 & 0.417 & 0.417 & 1.583 & 0.417 & 0.583 & $\underline{\underline{2.417}}$ & 0.583 \\
\hline 2 & 1.500 & $\underline{\underline{2.500}}$ & 0.500 & 0.500 & 1.500 & $\underline{\underline{2.500}}$ & 0.500 & 0.500 & 0.500 & 0.500 & 1.500 & 1.500 \\
\hline 3 & 1.417 & 0.583 & 0.583 & 0.417 & 0.417 & 0.583 & 0.417 & 0.417 & 0.417 & $\underline{\underline{2.583}}$ & 0.583 & 1.417 \\
\hline 4 & 1.583 & 1.417 & 0.583 & 0.417 & 1.417 & 0.583 & 0.583 & 0.417 & 0.583 & 0.417 & 0.417 & 0.583 \\
\hline 5 & 1.083 & 0.083 & 0.083 & 0.083 & 0.083 & 1.083 & 1.083 & $\underline{\underline{2.083}}$ & 1.083 & 0.083 & 1.083 & 1.083 \\
\hline 6 & 0.250 & 1.250 & 1.250 & 0.250 & 0.250 & 0.250 & 0.250 & 0.250 & 0.250 & 1.250 & 1.250 & 0.750 \\
\hline 7 & 0.917 & 0.083 & 0.917 & 1.917 & 0.083 & 0.917 & 0.083 & 1.083 & 0.083 & 1.083 & 1.083 & 1.083 \\
\hline 8 & 1.167 & 0.167 & 0.167 & 1.167 & 0.833 & 0.833 & 0.833 & 0.167 & 0.833 & 1.167 & 0.167 & 1.167 \\
\hline 9 & 0.05 & 0.05 & 0.05 & 0.05 & 0.05 & 0.05 & 0.05 & 1.05 & 0.05 & 1.05 & 1.05 & $\underline{\underline{2.05}}$ \\
\hline 10 & 0.833 & 0.833 & 0.167 & 0.833 & 0.167 & 0.167 & 0.833 & 1.167 & 0.833 & 1.167 & 0.167 & 1.167 \\
\hline 11 & 0.250 & 0.250 & 0.75 & 0.250 & 1.25 & 0.75 & 1.75 & 0.250 & 0.75 & 0.250 & 1.25 & 0.250 \\
\hline 12 & 0.333 & 1.333 & 0.333 & 0.667 & $\underline{\underline{3.333}}$ & 0.333 & 0.333 & 0.667 & 1.333 & 0.667 & 0.333 & 0.667 \\
\hline 13 & 0.917 & 0.917 & 0.917 & 0.917 & 0.083 & 0.917 & 0.917 & 0.917 & 0.083 & 0.917 & 0.083 & 0.917 \\
\hline 14 & 0.500 & 0.500 & 0.500 & 0.500 & 0.500 & 0.500 & 2.500 & $\underline{\underline{0.500}}$ & 1.500 & 0.500 & 1.500 & $\underline{\underline{2.500}}$ \\
\hline 15 & 0 & 1 & 1 & 0 & 2 & 1 & 1 & 0 & 1 & 1 & 2 & 2 \\
\hline 16 & 2 & 0 & 0 & 1 & $\underline{\underline{3}}$ & 0 & 1 & 2 & 1 & 1 & 2 & 0 \\
\hline 17 & 0.167 & 0.833 & 0.167 & 0.167 & 1.167 & 1.167 & 0.167 & 0.167 & 0.833 & 1.167 & 0.167 & 0.167 \\
\hline 18 & 0.500 & 1.500 & 0.500 & 0.500 & 0.500 & 0.500 & 0.500 & 1.500 & 0.500 & 1.500 & $\underline{\underline{2.500}}$ & 1.500 \\
\hline 19 & 0.750 & 0.750 & $\underline{\underline{2.250}}$ & 0.750 & 1.750 & 0.250 & 0.750 & 1.250 & 0.750 & 1.250 & $\underline{\underline{2.250}}$ & 1.750 \\
\hline 20 & 1.750 & 0.750 & 0.250 & 1.750 & $\underline{\underline{2.250}}$ & 0.250 & 0.250 & 0.750 & 0.750 & 1.750 & $\underline{\underline{2.250}}$ & 1.250 \\
\hline
\end{tabular}

Note: The first line is the number of experts, the first column is the index number, the underlined evaluation value does not meet the conditions of consistency. 
From the evaluation matrix and Table 4, it can be seen that on some indicators, some experts' assessments deviate from the center value.

(1) Experts 11 consider this project less viable in international competition;

(2) Experts 17 consider that the feasibility of domestic competition is high, while experts6 consider it relatively low;

(3) Expert 10 believes that the feasibility of the market size is high;

(4) Expert 8 considers the feasibility of reserve technology low;

(5) Experts 12 think that the feasibility of enterprise fees is high;

(6) According to expert 5, in the aspects of task completion and management personnel training, the feasibility of controlling risk of operation of the enterprise is low;

(7) Both expert 8 and expert 12 consider the feasibility of cooperation between the military and the enterprise low;

(8) Expert 5 thinks that the feasibility of management personnel training is low;

(9) Expert 11 thinks that it is feasible in risk control of material reserve damage and market risk control;

(10) Expert 5 thinks that the feasibility of controlling the operation risk of the enterprise is low.

The project implementation party requires experts who do not meet the assessment criteria to give specific reasons for the different opinions of an indicator. The statistical experts will send the results of the consistency analysis and experts' explanations of some indicators deviating from the opinions to all the experts so that Experts make a second evaluation.

The fourth step, the experts based on the feedback information for the second evaluation, through the consistency analysis, concluded that the results of the consistency analysis shown in Table 5.

Table 5 Results of the second round of consistency analysis

\begin{tabular}{|c|c|c|c|c|c|c|c|c|c|c|c|c|}
\hline & 1 & 2 & 3 & 4 & 5 & 6 & 7 & 8 & 9 & 10 & 11 & 12 \\
\hline 1 & 1.583 & 0.583 & 0.417 & 1.583 & 1.417 & 0.583 & 0.583 & 1.583 & 0.583 & 0.417 & 0.583 & 1.417 \\
\hline 2 & 1.500 & 1.500 & 0.500 & 0.500 & 1.500 & 1.500 & 0.500 & 0.500 & 0.500 & 0.500 & 1.500 & 1.500 \\
\hline 3 & 1.250 & 0.750 & 0.750 & 0.250 & 0.417 & 0.250 & 0.250 & 0.250 & 0.250 & 0.750 & 0.750 & 1.250 \\
\hline 4 & 1.583 & 1.417 & 0.583 & 0.417 & 1.417 & 0.583 & 0.583 & 0.417 & 0.583 & 0.417 & 0.417 & 0.583 \\
\hline 5 & 0.833 & 0.167 & 0.167 & 0.167 & 0.833 & 1.083 & 1.083 & 1.167 & 0.833 & 0.167 & 0.833 & 0.833 \\
\hline 6 & 0.250 & 1.250 & 1.250 & 0.250 & 0.250 & 0.250 & 0.250 & 0.250 & 0.250 & 1.250 & 1.250 & 0.750 \\
\hline 7 & 0.917 & 0.083 & 0.917 & 1.917 & 0.083 & 0.917 & 0.083 & 1.083 & 0.083 & 1.083 & 1.083 & 1.083 \\
\hline 8 & 1.167 & 0.167 & 0.167 & 1.167 & 0.833 & 0.833 & 0.833 & 0.167 & 0.833 & 1.167 & 0.167 & 1.167 \\
\hline 9 & 0.917 & 0.083 & 0.917 & 0.917 & 0.083 & 0.083 & 0.917 & 1.083 & 0.917 & 1.083 & 1.083 & 1.083 \\
\hline 10 & 0.833 & 0.833 & 0.167 & 0.833 & 0.167 & 0.167 & 0.833 & 1.167 & 0.833 & 1.167 & 0.167 & 1.167 \\
\hline 11 & 0.250 & 0.250 & 0.75 & 0.250 & 1.25 & 0.75 & 1.75 & 0.250 & 0.75 & 0.250 & 1.25 & 0.250 \\
\hline 12 & 0.083 & 1.083 & 0.083 & 0.917 & 1.083 & 0.083 & 0.083 & 0.917 & 1.083 & 0.917 & 0.083 & 0.917 \\
\hline 13 & 0.917 & 0.917 & 0.917 & 0.917 & 0.083 & 0.917 & 0.917 & 0.917 & 0.083 & 0.917 & 0.083 & 0.917 \\
\hline 14 & 0 & 1 & 0 & 1 & 0 & 0 & 1 & 1 & 1 & 1 & 1 & 1 \\
\hline 15 & 0 & 1 & 1 & 0 & 2 & 1 & 1 & 0 & 1 & 1 & 2 & 2 \\
\hline 16 & 1.583 & 0.417 & 0.417 & 1.417 & 1.583 & 0.417 & 0.417 & 1.417 & 0.417 & 1.417 & 1.583 & 0.417 \\
\hline 17 & 0.167 & 0.833 & 0.167 & 0.167 & 1.167 & 1.167 & 0.167 & 0.167 & 0.833 & 1.167 & 0.167 & 0.167 \\
\hline 18 & 0.500 & 1.500 & 0.500 & 0.500 & 0.500 & 0.500 & 0.500 & 1.500 & 0.500 & 1.500 & $\underline{\underline{2.500}}$ & 1.500 \\
\hline 19 & 1 & 1 & $\underline{\underline{2}}$ & 1 & 0 & 0 & 1 & 1 & 1 & 1 & 2 & 2 \\
\hline 20 & 1.500 & 0.500 & 0.500 & 1.500 & 0.500 & 0.500 & 0.500 & 0.500 & 0.500 & 1.500 & 1.500 & 1.500 \\
\hline
\end{tabular}

Note: The first line is the number of experts, the first column is the index number, the underlined 
evaluation value does not meet the conditions of consistency.

As can be seen from Table 5, through the second evaluation of experts, many experts evaluate the feasibility of each indicator

As a result of the adjustment, only experts 11 have different opinions on the control over the risk of material reserves and think that the project is more feasible in preventing the risk of material reserves from being damaged. Statistics require experts to give specific reasons 11, the second round of evaluation and given the specific reasons given to experts, the third round of evaluation scoring.

The fifth step, through the third round of experts given the feasibility evaluation results, the consistency analysis, all experts evaluate the results to meet the consistency conditions, the evaluation results of experts written in matrix form is as follows:

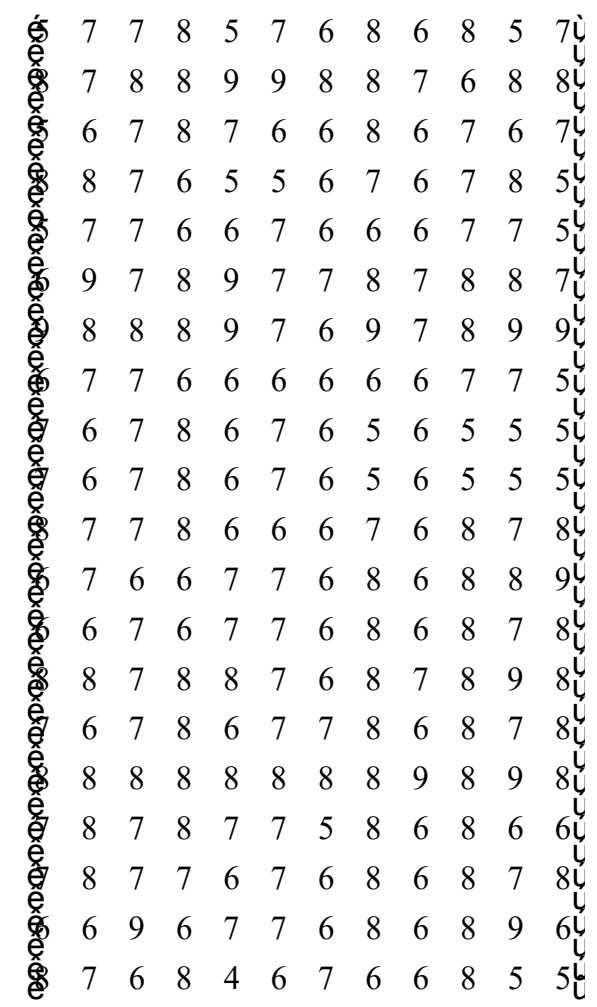

The sixth step, it should be noted here is that the project experts set the same weight, according to the level of experts, and some projects can consider setting different experts weight. The comprehensive score is the average of all the experts who meet the criteria of consistency. The weighted value is the product of the composite score and the weight. The degree of feasibility is the sum of the weighted values of all the indicators. The degree of feasibility of each index is shown in Table 6 Show. 
Table6 expert feasibility evaluation of the result

\begin{tabular}{|c|c|c|c|c|}
\hline $\begin{array}{l}\text { First level indicator } \\
\text { (weight) }\end{array}$ & Secondary indicators & Weights & $\begin{array}{l}\text { Comprehens } \\
\text { ive score }\end{array}$ & Weighted value \\
\hline \multirow{4}{*}{$\begin{array}{l}\text { Market-oriented } \\
\text { ability }(0.2)\end{array}$} & International competition & 0.05 & 6.58 & 0.329 \\
\hline & Domestic competition & 0.05 & 6.50 & 0.325 \\
\hline & Market development scale & 0.05 & 6.25 & 0.3125 \\
\hline & Competitive Advantage & 0.05 & 7.25 & 0.3625 \\
\hline \multirow{3}{*}{ technology $(0.2)$} & Reserve technology & 0.1 & 8.27 & 0.827 \\
\hline & Turnaround Technology & 0.05 & 6.25 & 0.3125 \\
\hline & Transport technology & 0.05 & 7.917 & 0.39585 \\
\hline \multirow[t]{3}{*}{ Financial ability } & Military budget & 0.05 & 7.943 & 0.39715 \\
\hline & Business fees & 0.025 & 6.917 & 0.172925 \\
\hline & Funding reserve & 0.025 & 6.833 & 0.17085 \\
\hline \multirow{3}{*}{ Mission protection } & Material delivery accuracy & 0.05 & 7.75 & 0.3875 \\
\hline & Task completion amount & 0.1 & 6.917 & 0.6917 \\
\hline & $\begin{array}{l}\text { After delivery material } \\
\text { well }\end{array}$ & 0.05 & 7.083 & 0.35415 \\
\hline \multirow[t]{3}{*}{ Human Resources } & $\begin{array}{l}\text { Military and business } \\
\text { docking }\end{array}$ & 0.1 & 7 & 0.7 \\
\hline & Technical personnel & 0.05 & 7 & 0.35 \\
\hline & Managerial talent & 0.05 & 6.583 & 0.32915 \\
\hline \multirow{4}{*}{$\begin{array}{l}\text { Market-oriented } \\
\text { ability }(0.2)\end{array}$} & Technical risk control & 0.025 & 7.833 & 0.195825 \\
\hline & $\begin{array}{l}\text { Material deterioration } \\
\text { damage risk control }\end{array}$ & 0.025 & 6.5 & 0.1625 \\
\hline & $\begin{array}{l}\text { Unpredictable risk control } \\
\text { in the market }\end{array}$ & 0.025 & 7 & 0.175 \\
\hline & $\begin{array}{c}\text { Corporate Operational } \\
\text { Risk Control }\end{array}$ & 0.025 & 6.5 & 0.1625 \\
\hline
\end{tabular}

The evaluation results of all the experts were weighted and the feasibility level of this project was 7.1086.

\section{Project feasibility evaluation results}

This article uses the improved Delphi method to calculate the 12 experts' comprehensive evaluation of the degree of feasibility of local enterprises for storage and readiness materials project 7.1086, according to the previous section, indicating that the project can be implemented, but there is also a certain degree of risk. Judging from the comprehensive evaluation results of various indicators, indicators with a size of less than 7 show that if the military wants to implement the project, the feasibility level must be raised on these indicators. Sometimes, the comprehensive evaluation of experts is just a reference for the implementation of the decision-making, not as a viable final judgment criteria, after all, the views of experts with one-sidedness, the introduction of a comprehensive evaluation of a number of experts also in order to minimize personal bias, improve reference Sex. Moreover, any group decision-making method is not perfect. In this paper, the weight of experts is not considered, and consensus is reached after the third cycle. If there are still unsatisfied conditions after three times, the evaluation result should be excluded, Not included in the comprehensive evaluation. 


\section{References}

[1] Yuan Jiyue.Multiple Attribute Group Decision Theory and Method [M]. Beijing: Economic Daily Press, 2010.

[2] Du Wei, Wang Wei, etc.Preparation for reserve preparation for combat readiness [J].Command and Control and Simulation, 2014 (6), 133-135.

[3] ZhaiXuemei, Li Changling. Delphi method and its application in creating knowledge-sharing enterprises [J]. Modern Information, 2006 (9), 185-190.

[4] Zhang Lihui, Li Xiaoding, etc.Using Delphi method to determine China's future nuclear energy development trend [R]. Nuclear Safety, 2016 (3), 74-78.

Journal of Northeastern University, 2016 (1), 115-117. [5] WANG Xue-jun, GUO Ya-jun, LAN Tian.Ordered relation analysis method of constructing consistency judgment matrix [J]

[6] Wang Baoli. Research on multi-attribute group decision making method based on kernel computing [J] .Journal of Shanxi University, 2016.

[7] Wei Hengfeng. Distribution data consistency [J].Nanjing University PhD thesis, 2013.

[8] Han-Mei Han, Gao Feng. A multi-attribute group decision-making method in quality assessment [J] .Hubei Coal Industry Teachers College, 2007 (2), 54-57.

[9] CHEN Yan-Gao, MA Guang-wen.Application of multi-attribute group decision in project risk assessment [J] .Hydraulic Power Generation, 2011 (7), 79-89.

By calculating the deviation from the consistency of the value of the results shown in Table 4, marked out of the allowable range of values 